\title{
Condições de segurança do trabalho no manuseio de agrotóxicos em pequenas propriedades de agricultura familiar
}

Os agricultores familiares durante aplicação e manuseio de agrotóxicos estão expostos a diversos riscos, devido à manipulação de produtos altamente tóxicos Dessa forma, este trabalho teve como objetivo conhecer o perfil socioeconômico dos agricultores familiares, identificar os procedimentos, riscos e as possibilidades de contaminações ambientais e humanas devido à utilização de agrotóxicos e verificar a utilização de equipamentos de proteção individual no manuseio dos mesmos em pequenas propriedades rurais no município de Juazeiro do Norte/CE. Trata-se de um estudo de campo, utilizando-se do método de análise de Abreu e Alonzo (2016), o qual baseou-se na aplicação de entrevistas semiestruturadas. O estudo foi aplicado num comodato do município. 0 comodato da Vila São Gonçalo é composto por trinta e seis agricultores. Participaram desse estudo dezoito agricultores familiares, compreendendo uma amostra de $50 \%$ do todo. Através dos resultados do estudo, verificou-se são aplicadas poucas medidas de controle de segurança do trabalho rural pelos agricultores familiares do estudo, devido à ausência de informação sobre os riscos, baixa escolaridade, perpetuação de antigas práticas de cultivo, quesito financeiro, sentimento de imunidade ao perigo e a falta de assistência de políticas públicas voltadas para o trabalhador rural, os quais, ficam expostos a riscos que são prejudicais para o meio ambiente e saúde dos mesmos. Assim, faz-se necessária a implantação de medidas de controle de segurança nas etapas de produção agrícola, para redução das suscetíveis ameaças à segurança do meio ambiente e saúde do pequeno produtor rural.

Palavras-chave: Pequeno Produtor Rural; Defensivos Agrícolas; Riscos Químicos; Meio ambiente; Saúde e Segurança.

\section{Work safety conditions in the handling of pesticides in small family farms}

\begin{abstract}
Family farmers during application and handling of pesticides are exposed to several risks due to the handling of highly toxic products. Thus, this work aimed to know the socioeconomic profile of family farmers, to identify the procedures, risks and the possibilities of environmental and human contamination due to the use of pesticides and to verify the use of personal protective equipment when handling them on small properties in the municipality of Juazeiro do Norte/CE. This is a field study, using the method of analysis by Abreu and Alonzo (2016), which was based on the application of semi-structured interviews. The study was applied to a municipal loan. The Vila São Gonçalo lending consists of thirty-six farmers. Eighteen family farmers participated in this study, comprising a sample of $50 \%$ of the whole. Through the results of the study, it was found that few measures for the control of rural work safety are applied by the family farmers in the study, due to the lack of information on the risks, low education, perpetuation of old farming practices, financial question, feeling of immunity to danger and the lack of assistance from public policies aimed at rural workers, who are exposed to risks that are harmful to the environment and their health. Thus, it is necessary to implement safety control measures in the stages of agricultural production, to reduce the susceptible threats to the safety of the environment and the health of the small rural producer.
\end{abstract}

Keywords: Small Rural Producer; Pesticides; Chemical Hazards; Environment; Health and safety.

\section{Topic: Engenharia Ambiental}

Reviewed anonymously in the process of blind peer.
Received: 01/12/2020

Approved: 23/12/2020
Lucy Nayandra Pereira e Silva (ii)

Instituto Federal do Ceará, Brasil

http://lattes.cnpq.br/5385220684739093

http://orcid.org/0000-0003-0744-3165

lucynayandraa@gmail.com

Joana Gabriela Barbosa Amorim (iD)

Instituto Federal do Ceará, Brasil

http://lattes.cnpq.br/8842128519205373

http://orcid.org/0000-0002-4805-5014

joana.barbosa@ifce.edu.br
Referencing this:

SILVA, L. N. P.; AMORIM, J. G. B.. Condições de segurança do trabalho no manuseio de agrotóxicos em pequenas propriedades de agricultura familiar. Revista Ibero Americana de Ciências Ambientais, v.11, n.7, p.349-364, 2020. DOI: http://doi.org/10.6008/CBPC2179$\underline{6858.2020 .007 .0029}$

DOI: $10.6008 / C B P C 2179-6858.2020 .007 .0029$ 


\section{INTRODUÇÃO}

A agricultura é uma das principais atividades econômicas do Brasil e influencia significativamente no desenvolvimento do país. A atividade do setor agrícola é hoje a principal locomotiva da economia brasileira e corresponde a, aproximadamente, 100 bilhões de reais em volume de exportações em conjunto com a pecuária, segundo os dados publicados em 2016 pela Secretaria de Relações Internacionais do Ministério da Agricultura, Pecuária e Abastecimento.

A agricultura familiar representa um importante segmento do setor agropecuário brasileiro. Conforme a Lei $n^{\circ}$ 11.326, de 24 de julho de 2006 que estabelece as diretrizes para a formulação da Política Nacional da Agricultura Familiar (Pronaf) e Empreendimentos Familiares Rurais. São enquadrados como agricultor familiar aquele que pratica atividades no meio rural com sua família e que não possua uma área maior do que quatro módulos fiscais, sua mão de obra ser prioritariamente familiar e sua renda familiar tenha o percentual mínimo advindo da sua atividade agrícola (BRASIL, 2006).

Com a modernização agrícola brasileira e o desafio de produzir cada vez mais, sem aumentar a área de produção, diferentes tecnologias foram disseminadas, a partir da década de 1950, mediante introdução da chamada Revolução Verde, que transformou e influenciou as áreas de produção agrícolas e redirecionou as práticas da agricultura familiar com a inserção de outras estratégias de produção tais como os agrotóxicos (LOPES et al., 2018).

Agrotóxicos são produtos químicos utilizados na agricultura para controlar doenças, insetos, ou plantas daninhas que causam danos às plantações. A maior problemática do uso de agrotóxicos se iniciou devido às incertezas quanto a sua segurança para a saúde humana e animal, bem como para o meio ambiente. Atualmente, existe maior interesse em desenvolver novas tecnologias para incrementar a produção a um baixo custo, geralmente desconsiderando os aspectos à saúde e segurança do produtor e da população em geral (AMARAL, 2013).

Segundo a Agência Nacional de Vigilância Sanitária (Anvisa), os agrotóxicos podem ser classificados de acordo com sua toxicidade. Além da classificação toxicológica, os agrotóxicos também podem ser classificados quanto ao tipo de praga a que se destinam o seu controle (PERES et al., 2003). Para o registro dos agrotóxicos, o mesmo passa pela avaliação de três órgãos do governo federal, cada qual com uma responsabilidade especifica são eles: Ministério da Agricultura, Pecuária e Abastecimento (Mapa), Ministério do Meio Ambiente (MMA) e o Ministério da Saúde (MS).

$\mathrm{Na}$ atualidade, o Brasil destaca-se por ser pioneiro no uso de agrotóxicos em seus cultivos agrícolas no meio rural, devido a modernização da agricultura, acarretando em uma série de consequências tanto a saúde e segurança do trabalhador quanto para o meio ambiente. Segundo dados do IBGE (2017), o número de estabelecimentos que admitiram usar agrotóxicos aumentou 20,4\% nos últimos 11 anos.

No Brasil, segundo o Sistema de Informação de Agravos de Notificação (2017), mais de 5 mil casos de intoxicação por agrotóxico agrícola são registrados a cada ano, além disso, considera-se que estes números podem ser subestimados devido a elevada subnotificação desses eventos no País (SINAN, 2017). 
As pessoas mais suscetíveis aos perigos de contaminação por agrotóxicos são aquelas que tem contato no campo, incluindo os de contato direto desde os aplicadores, preparadores de caldas e responsáveis por depósitos, como também os trabalhadores de contato indireto com os venenos ao realizar capinas, roçadas, colheitas, estes por sua vez, considera-se como de maior risco, pois muitas vezes não respeitam o intervalo de reentrada nas lavouras sem uso de proteção após aplicação dos insumos químicos (LONDRES, 2011).

Diante disso, é notório que o uso de agrotóxicos no ambiente rural brasileiro vem provocando inúmeras consequências, tanto no quesito ambiental quanto para a saúde do trabalhador. De modo geral, isso resulta do uso inadequado dessas substâncias, da pressão efetuada pelas indústrias e comércios, da elevada toxicidade de alguns produtos, da ausência de informações a respeito da saúde e segurança dos trabalhadores e da precariedade dos mecanismos de vigilância (MONQUERO et al., 2009, citado por ISMAEL et al., 2015). Dessa forma, a exposição ao uso de insumos químicos na agricultura está relacionada a diversos efeitos à saúde humana, com evidentes aumentos no número de doenças variadas.

É evidente o grau de risco que os trabalhadores ficam expostos na utilização de agrotóxicos, sendo necessário aplicação de medidas de controle, que são previstas na legislação trabalhista brasileira, abordando conceitos voltados a segurança do trabalho na agricultura, como por exemplo a Norma Regulamentadora 06 que dispõe sobre Equipamento de Proteção Individual (EPI), a Norma Regulamentadora 09 que dispõe sobre Programa de Prevenção de Riscos Ambientais e a Norma Regulamentadora 31 que dispõe sobre Segurança e Saúde no Trabalho na Agricultura, Pecuária, Silvicultura, Exploração Florestal e Aquicultura.

A precariedade dos usos de EPIs pelos trabalhadores rurais brasileiros se tornou um problema de saúde pública. Especialmente em pequenas propriedades produtoras, é comum deparar-se com trabalhadores sem os EPIs obrigatórios durante a manipulação e a aplicação de agrotóxicos, mesmo com toda a densa legislação brasileira vigente voltada para segurança do trabalho.

Assim, esta pesquisa teve como objetivo avaliar as condições de segurança do trabalho no manuseio de agrotóxicos em pequenas propriedades rurais no município de Juazeiro do Norte/CE, em seguida, estabelecer o perfil socioeconômico dos agricultores familiares, identificar os procedimentos e os riscos da utilização de agrotóxicos pelos agricultores em suas propriedades, além de verificar o uso de Equipamentos de Proteção Individual por parte dos agricultores e identificar possibilidades de contaminações ambientais e humanas devido ao emprego de agrotóxico pelos produtores.

\section{METODOLOGIA}

\section{Caracterização da área de estudo}

Juazeiro do Norte é um município brasileiro do estado do Ceará, localizado na mesorregião do Sul Cearense, microrregião do Cariri, com população estimada de 271.926 habitantes e densidade demográfica de $1.004,45 \mathrm{hab} / \mathrm{km}^{2}$. Sua área é de $248,8 \mathrm{~km}^{2}$, distante da capital do estado a $396,0 \mathrm{~km}$ em linha reta, 
apresenta uma altitude média de $377,3 \mathrm{~m}$, tem como coordenadas geográficas de $7^{\circ} 12^{\prime} 47^{\prime \prime}$ de latitude sul e $39^{\circ} 18^{\prime} 55^{\prime \prime}$ de longitude oeste (IPECE, 2017).

O estudo foi aplicado num comodato (Figura 1), pertencente a Vila São Gonçalo, em Juazeiro do Norte/CE, localizado ao norte do município, distante $12 \mathrm{~km}$ do centro da cidade, cujo as coordenadas geográficas são $7^{\circ} 11^{\prime} 03.64^{\prime \prime}$ de latitude Sul e $39^{\circ} 13^{\prime} 38.21^{\prime \prime}$ de longitude Oeste.

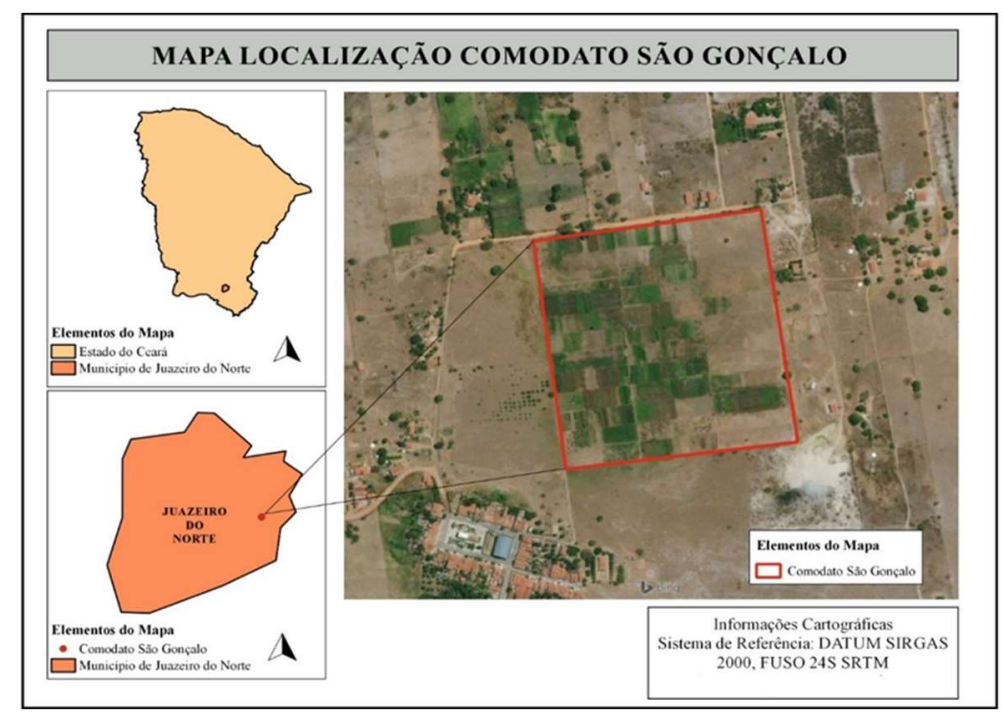

Figura 1: Mapa de localização do comodato São Gonçalo.

O comodato da Vila São Gonçalo é composto por trinta e seis agricultores. Cada agricultor é responsável por 1 tarefa de terra no comodato, que equivale a 0,3 hectares de terras, totalizando 10,8 hectares. Além disso, o comodato possui duas estufas compartilhadas que correspondem a 0,5 hectares de terra no total, no qual oito agricultores são responsáveis pelo cultivo de hortaliças do local.

Os tipos de culturas cultivadas no comodato são hortaliças, frutíferas e leguminosas diversas. A comercialização dos produtos vai para o banco de alimentos do Programa de Aquisição de Alimentos (PAA), Programa Nacional de Alimentação Escolar (PNAE) e distribuição em mercados locais. Todos os agricultores e suas famílias do referido comodato são atendidos pelo Pronaf. Não se sabe ao certo há quanto tempo a comunidade existe, no entanto, o financiamento pelo Pronaf iniciou no ano de 2012.

Para auxiliar no cultivo, os agricultores contam com um sistema de irrigação convencional automatizado, no qual, a fonte de água para esse sistema é subterrânea através de três poços distribuídos na área total do comodato. Esse tipo de sistema é aquele que utiliza os componentes convencionais de aspersão (motobombas, tubulações e aspersores), nesse caso eles são fixos, ou seja, permanecem parados na mesma posição ao longo do período de produção, cobrindo toda a área irrigada.

\section{Coleta e Análise de dados}

O trabalho de campo foi desenvolvido nas propriedades de agricultura familiar, entre os meses de outubro e dezembro de 2019, com o auxílio da Empresa de Assistência Técnica de Extensão Rural do Ceará (Ematerce) do Município de Juazeiro do Norte/CE, responsável pela indicação da área da pesquisa, localização e acesso aos agricultores da área delimitada para o estudo. A pesquisa foi realizada por meio de 
visitas direcionadas as propriedades para a coleta de informações específicas relacionadas ao tema abordado, ou seja, referentes à forma pelo qual o produtor rural adquire e utiliza os agrotóxicos no desenvolvimento das atividades rurais, e ainda de que forma isso afeta sua saúde, seu modo de vida e o meio ambiente. O local escolhido se deu pela representatividade do cenário real desses pequenos agricultores do município de Juazeiro do Norte/CE, além da facilidade do acesso as propriedades e aos agricultores, conforme sugerido pelo representante da Ematerce.

Para levantamento dos dados, realizou-se a aplicação das entrevistas semiestruturadas com 18 dos agricultores familiares que fazem uso de agrotóxicos em seus cultivos, compreendendo uma amostra de $50 \%$ do todo. Como critério para a definição da amostra, utilizou-se da escolha de um universo que fazem uso de agrotóxicos na sua cultura e utilizando-se metade dessa população, dando um equilíbrio entre a população escolhida para a amostra e a população total da área de estudo, além da singularidade de ser um número considerável para aplicação de uma pesquisa.

Neste estudo, os critérios de inclusão dos sujeitos foram: ser maior de 18 anos de idade, residir no município, fazer uso de agrotóxicos, estar desenvolvendo atividades agrícolas no momento da pesquisa e aceitar participar voluntariamente da pesquisa.

As perguntas foram elaboradas com base no método de estudo de Abreu et al. (2016), que realizaram um levantamento sobre Agricultor familiar e o uso (in)seguro de agrotóxicos no município de Lavras/MG, na qual, chamou atenção pela forma que abordou as unidades produtivas de agricultura familiar segundo práticas de trabalho relacionadas ao uso de agrotóxicos.

Posteriormente, foi construído um banco de dados, com as informações obtidas por meio das entre vistas com os proprietários rurais, e analisou-se as características socioeconômicas dos agricultores familiares, tipos de culturas e aspectos de segurança no trabalho, como as práticas de trabalho relacionadas ao uso de agrotóxicos.

\section{RESULTADOS E DISCUSSÃO}

\section{Aspectos Socioeconômicos e tipos de culturas}

Após o levantamento de dados, efetuou-se a análise e tabulação dos dados dos relacionados as entrevistas. Em relação ao gênero e a faixa etária, dentre os agricultores entrevistados, observou-se a predominância do sexo masculino, correspondendo a 100\% da amostra estudada, compreendendo uma faixa etária entre 30 e 50 anos (50\%), seguidos de agricultores maiores que 50 anos (44\%) e com faixa etária entre 18 e 30 anos (6\% da amostra). Constatou-se, então, que os homens estão mais vulneráveis aos riscos decorrentes ao manuseio de agroquímicos.

Esses resultados são justificados pela influência da modernização agropecuária, no processo de êxodo rural das mulheres e dos jovens no campo, em busca de novas oportunidades no mercado de trabalho formal, além do campo agrícola. Como cita Maia et al. (2015, citado por PAULA, 2018) sobre a masculinização no campo, que se deve "As transformações agrícolas, o uso intensivo de tecnologia [..], a redução da 
demanda de trabalho físico/braçal, privilegia a contratação de mão de obra permanente ou temporária masculina, aumentando a segregação de gênero".

Outro aspecto importante refere-se ao nível de instrução das pessoas responsáveis pelas propriedades rurais, no qual, apresentaram uma baixa escolaridade com um percentual de $22 \%$ analfabetos, $50 \%$ ensino fundamental incompleto, $6 \%$ ensino fundamental completo e apenas $22 \%$ concluíram o ensino médio. De acordo com Francisco et al. (2014) esses relevantes índices de analfabetismo no campo podem estar relacionados a ausência de escolas nas zonas rurais ou condições péssimas de funcionamento das escolas aliado ao incentivo dos pais aos filhos para ajudarem desde cedo na agricultura.

A baixa escolaridade, predominante entre os agricultores, torna as informações contidas nas embalagens e rótulos dos agrotóxicos de difícil compreensão, contribuindo para o risco de intoxicação (SILVEIRA, 2011).

No que diz respeito a renda mensal dos agricultores, os salários variam ao longo do ano, devido aos aspectos climáticos e em função do próprio manuseio da cultura, mas em média os agricultores afirmam receber 1 salário mínimo (45\%), menor que 1 salário (33\%) e recebem entre 1-2 salários (22\%). Da totalidade, $28 \%$ ainda contam com a complementação de renda proveniente do bolsa família e $33 \%$ com a aposentadoria.

Todos os entrevistados afirmaram ter cultivo no comodato desde o ano de 2012, com um tempo de cultivo no mesmo de aproximadamente oito anos. Os tipos de cultura do comodato são diversificados, dentre eles se destacam $35 \%$ de cultivo misto de leguminosas e hortaliças, $30 \%$ só de hortaliças, $29 \%$ de hortaliças e frutíferas e $6 \%$ de frutíferas e leguminosas. Os principais tipos de cultura mencionados foram: coentro, alface, repolho, cebola, cebolinha, pimenta, pimentão, batata, milho, feijão, pepino maxixe, quiabo, pequi, berinjela, abobora, macaxeira, limão e banana, que são comercializados para o banco de alimentos do PAA, PNAE e distribuição em mercados locais.

\section{Aspectos de Segurança no Trabalho}

\section{Uso de agrotóxicos}

Com relação às informações coletadas sobre o uso de algum tipo de defensivo agrícola nas áreas de cultivo, verificou-se que $100 \%$ dos agricultores utilizam agrotóxicos. De acordo com Veiga (2007), "os agrotóxicos são os recursos mais utilizados pelos produtores rurais para tentar compensar a perda de produtividade provocada pela degradação do solo e muitas vezes é a única forma de controlar o aparecimento de pragas e doenças".

A tabela 1 apresenta o grupo dos principais agrotóxicos utilizados pelos entrevistados, sua classificação toxicológica e a classificação de periculosidade ambiental, verificando assim o grau de risco de exposição desses agricultores a manipulação desses produtos.

De acordo com a NR 31, no item 31.3.3 deve-se "realizar avaliações dos riscos para a segurança e saúde dos trabalhadores e, com base nos resultados, adotar medidas de prevenção e proteção" (BRASIL, 
2005, p. 1) para garantir a segurança e saúde dos trabalhadores. Portanto, verificou-se a predominância de manipulação de agrotóxicos extremamente tóxico e medianamente tóxico pelos agricultores, com um grau alto de periculosidade ambiental, necessitando assim de cuidados para prevenção de riscos tanto para saúde deles quanto para o meio ambiente.

Tabela 1: Agrotóxicos utilizados na propriedade e sua classificação toxicológica e ambiental.

\begin{tabular}{|c|c|c|c|}
\hline Agrotóxicos & Classe & $\begin{array}{l}\text { Classificação } \\
\text { Toxicológica }\end{array}$ & $\begin{array}{l}\text { Classificação do Potencial de Periculosidade } \\
\text { Ambiental }\end{array}$ \\
\hline Decis $25 \mathrm{EC}$ & Inseticida & I- Extremamente Tóxico & $\begin{array}{l}\text { I- Produto Altamente Perigoso ao Meio } \\
\text { Ambiente }\end{array}$ \\
\hline Klorpan 480 EC & Inseticida & I- Extremamente Tóxico & II- Produto Muito Perigoso ao Meio Ambiente \\
\hline Lannate BR & Inseticida & I- Extremamente Tóxico & II- Produto Muito Perigoso ao Meio Ambiente \\
\hline Manzate 800 & Fungicida & I- Extremamente Tóxico & II- Produto Muito Perigoso ao Meio Ambiente \\
\hline DMA 806 BR & Herbicida & I- Extremamente Tóxico & III- Produto Perigoso ao Meio Ambiente \\
\hline Targa $50 \mathrm{EC}$ & Herbicida & I- Extremamente Tóxico & II- Produto Muito Perigoso ao Meio Ambiente \\
\hline Cartap BR 500 & Inseticida/ Fungicida & I- Extremamente Tóxico & III- Produto Perigoso ao Meio Ambiente \\
\hline Karate $50 \mathrm{EC}$ & Inseticida & II- Altamente Tóxico & $\begin{array}{l}\text { I- Produto Altamente Perigoso ao Meio } \\
\text { Ambiente }\end{array}$ \\
\hline $\begin{array}{l}\text { Glifosato } \\
\text { Nurfam }\end{array}$ & Herbicida & II- Altamente Tóxico & III- Produto Perigoso ao Meio Ambiente \\
\hline Actara 250 WG & Inseticida & $\begin{array}{l}\text { III- } \quad \text { Medianamente } \\
\text { Tóxico }\end{array}$ & III- Produto Perigoso ao Meio Ambiente \\
\hline Afalon $450 \mathrm{SC}$ & Herbicida & $\begin{array}{l}\text { III- } \quad \text { Medianamente } \\
\text { Tóxico }\end{array}$ & II- Produto Muito Perigoso ao Meio Ambiente \\
\hline Vertimec $18 \mathrm{EC}$ & Acaricida/Inseticida/Nematicida & $\begin{array}{l}\text { III- } \\
\text { Tóxico }\end{array}$ & II- Produto Muito Perigoso ao Meio Ambiente \\
\hline
\end{tabular}

Dentre os agrotóxicos utilizados pelos agricultores o de maior predominância foram os inseticidas com (71\%), herbicidas (16\%) e inseticida/fungicida (7\%) os demais percentuais estão divididos entre os outros grupos, como mostra o gráfico 1.

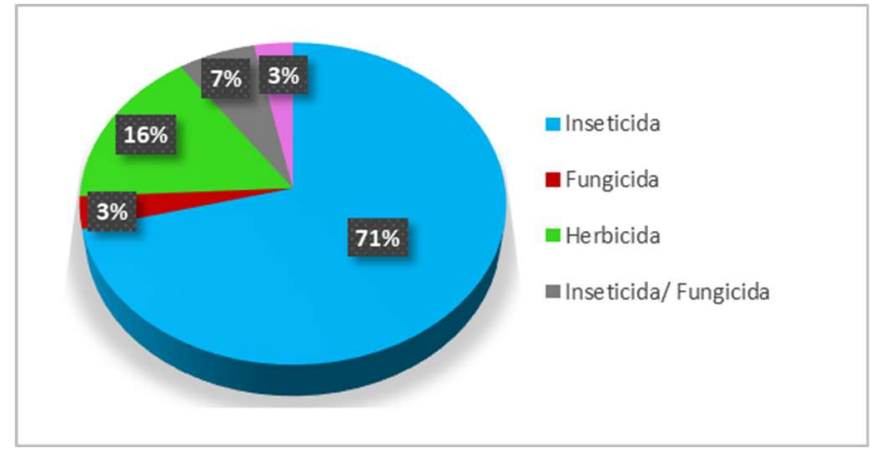

Gráfico 1: Classificação dos agrotóxicos, utilizados pelos agricultores entrevistados, quanto ao seu grupo químico.

Segundo Recena et al. (2008) o aumento do uso de inseticidas na agricultura deve-se claramente ao processo de resistências das pragas aos produtos químicos aplicados.

O uso de inseticidas no processo de produção agrícola está relacionado a diversos riscos que estão diretamente associados a uma série de consequências para meio ambiente e saúde do trabalhador rural. Segundo Machado (2010, citado por SILVA et al., 2017) os usos desses produtos tóxicos estão relacionados a diversas patologias no sistema imunológico, endócrino, e provocam alterações hepáticas, câncer, disfunções na tireoide, abortos, partos prematuros, doenças neurológicas, hiperatividade em crianças. Os grupos de maior risco de intoxicação por agrotóxicos (tanto aguda como crônica) são as pessoas que, no campo ou na indústria, ficam expostas ao contato direto com os venenos. 
De acordo com Folgado (2014) os problemas ambientais ocasionados pelos agrotóxicos são amplos, visto que eles contaminam a terra, que por sua vez, matam os microrganismos, o que a torna infértil, já que são estes organismos vivos que a fazem produtiva. Com esse processo de infertilização da terra, surge a necessidade de aumentar o uso de fertilizantes químicos, que por sua vez, alimentam as plantas e não recuperam a terra, gerando um ciclo vicioso entre agrotóxicos e fertilizantes.

Quando perguntados se usam mais de um tipo de insumo químico em sua propriedade, $50 \%$ dos agricultores responderam que utilizam apenas 1 tipo, 33\% utilizam 2 tipos e 17\% utilizam 3 tipos de agrotóxicos, dentre as diversas classes existentes. Essa variação está relacionada ao tipo de plantio de cultivo de cada agricultor. De acordo com Cizenando (2012) na busca para aumento da produção afim de evitar perda em seu cultivo, os produtores costumam usar mais de um insumo químico para combater as pragas e plantas daninhas.

Durante a entrevista, os agricultores afirmam que a manipulação dos agrotóxicos é realizada apenas por eles, não possuindo ajuda de nenhum familiar no uso desses produtos. O que em parcela diminui os riscos de contaminação entre os membros da família, porém não reduz totalmente esse risco, visto que a contaminação pode ocorrer de maneira indireta, como no contanto com EPIs contaminados durante a lavagem ou disposição do mesmo em suas residências.

\section{Tempo de exposição diária aos agrotóxicos}

No que diz respeito ao tempo de exposição diária na aplicação dos agrotóxicos, os agricultores familiares afirmam que 33\% ficam expostos menos de 1 hora, 56\% ficam em torno de 1 hora e $11 \%$ passam mais de 2 horas expostos a esse produto.

Segundo Silva (2016), as situações de riscos e a alta probabilidade dos agricultores adoecerem decorrem de um lado da própria toxidade dos produtos e, do outro, do tempo de exposição. Ainda que o produto tenha baixo nível de toxidade, caso haja uma exposição prolongada, é alto o risco de contaminação, assim como o inverso também é verdadeiro, ou seja, se o grau de toxidade é elevado, mesmo que o tempo de exposição seja curto, o risco de contaminação também é significativo.

No que se refere a exposição direta do empregador rural aos agrotóxicos, a NR 31, item 31.8.8 estabelece a obrigatoriedade de capacitação, com carga horária mínima de 20 (vinte) horas, visando diminuir os índices de contaminação pelos agrotóxicos (BRASIL, 2005). Nesses treinamentos deve-se abordar alguns conteúdos mínimos que são os conhecimentos das formas de exposição direta e indireta aos agrotóxicos, bem como saber identificar os sinais e sintomas de intoxicação e medidas de primeiros socorros, ter noção sobre rotulagem e sinalização de segurança, medidas higiênicas durante e após o trabalho, verificar a importância do uso de vestimentas e equipamentos de proteção pessoal, limpeza e manutenção dos mesmos. Entretanto, verificou-se que os entrevistados não tiveram acesso à essas informações.

\section{Aquisição dos agrotóxicos}

No que diz respeito a compra dos agrotóxicos com receita agronômica, 100\% dos agricultores 
afirmam que a aquisição é realizada diretamente no local de venda e sempre fazem a aquisição dos mesmos sem receituário e orientação técnica para utilização de agrotóxico ou afim. No entanto, de acordo com o art. 64 do decreto № 4.074, instituído em 4 de janeiro de 2002, os agrotóxicos e afins só poderão ser comercializados diretamente ao usuário, mediante apresentação de receituário próprio emitido por profissional legalmente habilitado, isso é necessário devido ao grau de risco na manipulação de produtos perigosos (BRASIL, 2002). Além disso, conforme Abreu et al. (2016) e os manuais de segurança, é no momento da compra do produto que são dadas as informações e instruções acerca dos procedimentos e cuidados a serem seguidos em cada atividade de manipulação dos agrotóxicos.

\section{Transporte dos agrotóxicos}

No que refere- se ao tipo de veículo usado pelos agricultores para transportar os agrotóxicos até as propriedades, os entrevistados afirmam que $67 \%$ utilizam moto, $22 \%$ utilizam caminhonete, $11 \%$ utilizam ônibus (transporte público) para transportar os insumos químicos.

Durante as visitas, verificou-se o transporte dos agrotóxicos junto com outras cargas no transporte até as residências. De acordo com Abreu et al. (2016) o agricultor familiar que reside na zona rural ao se deslocar para cidade, busca aproveitar o descolamento até o meio urbano para realizar o máximo de atividades possíveis. Visando economizar tempo e recurso, não realizam duas viagens, sendo uma para transporte dos agrotóxicos e outra para os demais produtos.

No entanto, vale ressaltar que devido ao grau de periculosidade dos agrotóxicos, a NR 31 traz algumas restrições sobre o tipo de veículo que deve ser utilizado para transportá-los. De acordo a referida NR, em seu item 31.8.19.1 é proibido transportar agrotóxicos, adjuvantes e produtos afins, em um mesmo compartimento que contenha alimentos e utensílios de uso pessoal e doméstico. Bem como transportar conjuntamente trabalhadores e agrotóxicos em veículos que não possuam compartimentos projetados para tal finalidade (BRASIL, 2005).

Fica vedado transportar os agrotóxicos em moto e ônibus, pois não possuem compartimento separado, levando junto pessoas, cargas e agrotóxicos. Nesse caso, apenas os que utilizam veículo do tipo caminhonete realizam o transporte de maneira correta. Vale lembrar ainda, sobre a importância de realizar a higienização do veículo sempre que forem destinados para outros fins.

\section{Armazenamento dos agrotóxicos}

Com relação ao local de armazenamento dos agrotóxicos pelos agricultores, eles afirmam que $20 \%$ armazenam em construção independente de alvenaria e coberta (casinha, garagem externa), 22\% armazenam dentro de casa e 50\% armazenam ao ar livre. Considerando que segundo a NR 31, nos itens 31.8.16 e 31.8.17 é proibido o armazenamento de agrotóxicos, adjuvantes e produtos afins a céu aberto, bem como a armazenagem em edificações devem conter paredes e coberturas resistentes, acesso restrito para os trabalhadores devidamente capacitados para o manuseio do produto, possuir ventilação, ter afixados placas ou cartazes com símbolo de perigo, além de ser distantes trinta metros das habitações e locais onde 
são guardados e consumidos alimentos, medicamentos, fontes de água ou outros materiais (BRASIL, 2005).

O armazenamento inadequado das embalagens de agrotóxicos traz consequências tanto para o meio ambiente quanto para saúde humana. Visto que, de acordo com Bernardi et al. (2018) a Organização Mundial da Saúde (OMS) alerta que a intoxicação gera uma grande preocupação para os produtores que utilizam produtos tóxicos, e que diversas vezes armazenam as embalagens em locais impróprios, ou até mesmo no manuseio sem as devidas precauções. O meio ambiente também é uma grande vítima do manuseio incorreto das embalagens de agrotóxicos, tanto as embalagens que são jogadas no solo, devido a contaminação e tempo de decomposição, como também os rios que sofrem contaminação por esses poluentes, devido à lavagem ou lançamento dessas embalagens no mesmo.

Através das visitas e entrevistas, verificou-se que os agricultores do comodato não seguem os requisitos estabelecidos pela legislação para armazenamento correto dos agrotóxicos, devido eles armazenarem a céu aberto, dentro de suas residências e em locais que não seguem os critérios mínimos com ventilação, sinalização de perigo através de placas e limpeza.

Com mostra a Figura 2 abaixo, é possível observar que o armazenamento não segue os critérios de armazenamento disposto na NR 31 no item 31.8.18, no qual as embalagens devem ser colocadas sobre estrados, evitando contato com o piso e afastadas das paredes e do teto (BRASIL, 2005).

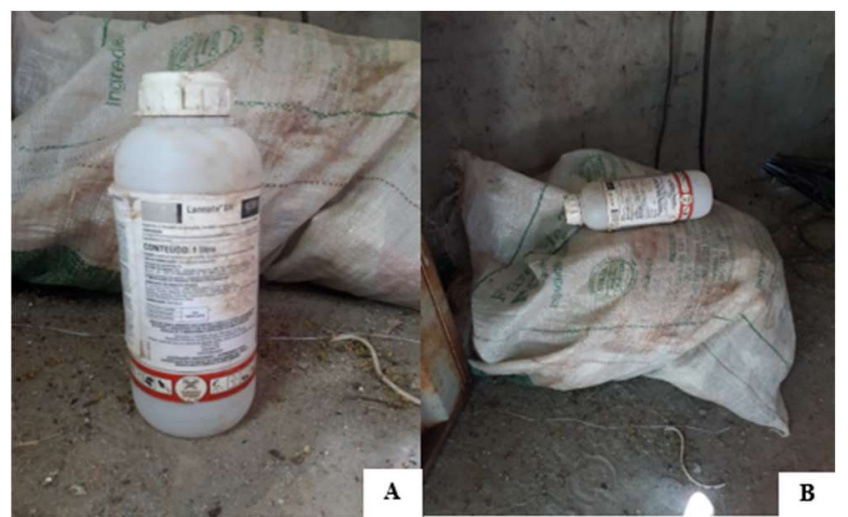

Figura 2: Embalagens dispostas sobre o piso (A) e Embalagens dispostas em contato com a parede (B).

Mesmo para estocagem de pequenas quantidades de produtos fitossanitários em propriedades rurais, as embalagens devem ser colocadas sobre estrados, evitando contado com o piso. As pilhas devem ser estáveis e afastadas das paredes e tetos, assim como as portas devem permanecer trancadas para evitar a entrada de crianças e animais, além da sinalização para demonstrar que é um local de armazenagem de produtos perigosos, porém foi possível observar que os mesmos são armazenados de forma desordenada e sem nenhum cuidado e critério.

Salienta-se que pela ausência de capacitação os agricultores não apresentam um amplo conhecimento sobre armazenamento correto dos agrotóxicos, favorecendo ao não cumprimento das exigências estabelecidas pela norma.

\section{Uso de EPIs no preparo e aplicação de agrotóxicos}

Quando perguntados sobre a utilização de todos os itens de equipamento de proteção individual no 
preparo e aplicação dos agrotóxicos, 39\% afirmam que sempre usam EPI, $44 \%$ as vezes e $17 \%$ nunca usam. Sendo que, os EPIs citados por eles foram apenas bota e máscara (17\%), bota e luva (11\%), apenas bota (44\%), EPI completo (11\%) e os outros (17\%) não usam nenhum tipo de EPI, conforme Gráfico 2.

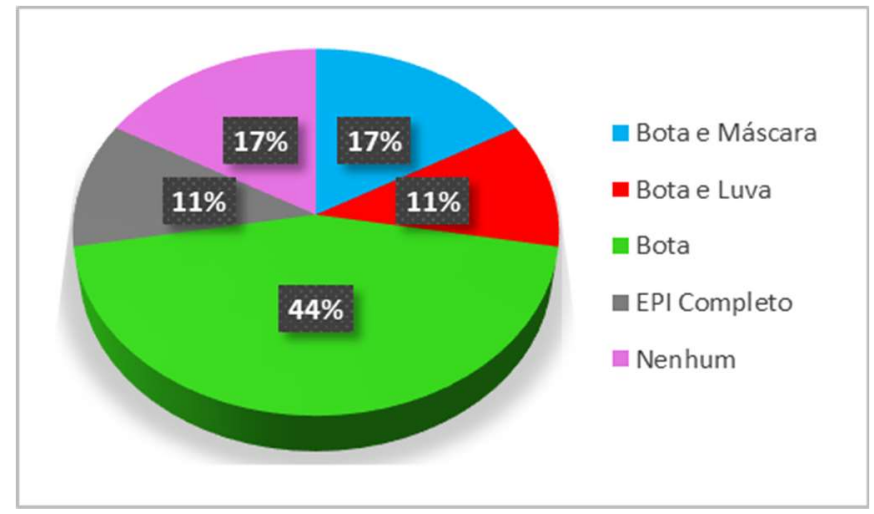

Gráfico 2: EPIs utilizados pelos agricultores entrevistados durante o preparo e aplicação dos agrotóxicos.

Segundo o manual de uso correto e seguro de produtos fitossanitários/ agrotóxicos da Andef (2008) o uso dos EPI é fundamental para reduzir o risco de absorção do produto tóxico pelo organismo, protegendo a saúde do trabalhador. Considera-se EPIs completos a utilização combinada de calça, jaleco, botas, avental, máscara, viseira, boné árabe e luva. Vale ressaltar que todo EPI deve ter o certificado de aprovação (CA) emitido pelo Ministério do Trabalho, conforme estabelecido pela NR 6 (BRASIL, 1978).

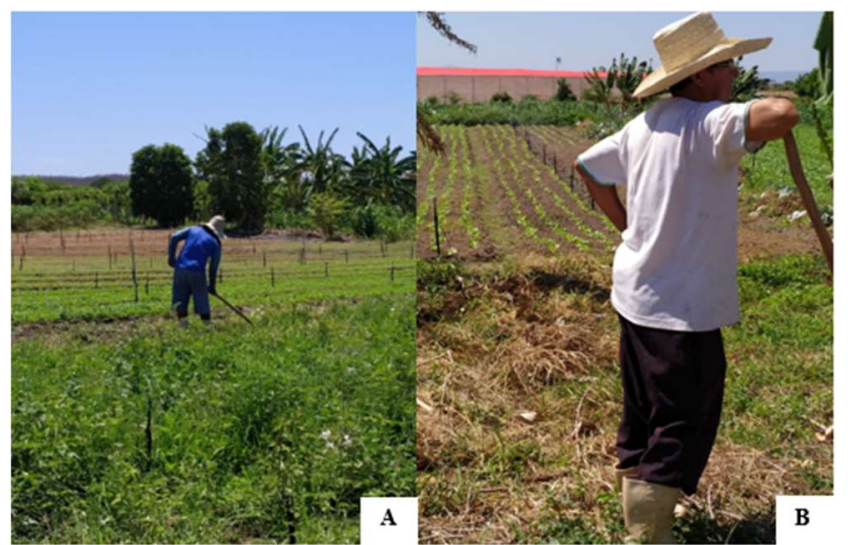

Figura 3: Uso de EPIs, bota e capuz (A) e apenas bota (B) no processo de produção agrícola pelos agricultores.

Vale ressaltar que, a etapa de preparo e aplicação envolvem grandes riscos de exposição e intoxicação, pois estão em contato direto com os agrotóxicos. Sendo que a ausência de EPIs pelos agricultores aumenta ainda mais a probabilidade de problemas de saúde, dessa forma é evidente a obrigatoriedade do equipamento de proteção individual. Entretanto, no comodato em estudo, apenas $11 \%$ usam o EPI completo, os demais alegam ausência no uso devido as condições financeiras e também por serem considerados desconfortáveis, além do pouco conhecimento para relacionar os problemas de saúde ao uso de agrotóxicos. Durante as visitas, foi possível observar o não uso do EPI completo pelos agricultores em nenhuma etapa do processo de produção agrícola, incluindo no manuseio e aplicação dos agrotóxicos, conforme mostra a figura 3. Quando questionados se durante o preparo já tinha respingado agrotóxico em alguma parte do corpo deles, $61 \%$ afirmaram que sim e apenas 39\% disseram que não. Esses incidentes ocasionados durante o 
manuseio, deve-se a não utilização do EPI durante o preparo da calda, sendo de suma importância para garantir a segurança dos trabalhadores.

\section{Destino final das embalagens vazias de agrotóxicos}

Verificou-se que com relação ao descarte das embalagens vazias, $5 \%$ devolve ao local de aquisição do produto, $44 \%$ queima, $6 \%$ joga no lixo comum, $6 \%$ reutiliza para outros fins e $39 \%$ juntam e entregam a um ponto de coleta municipal para embalagens de agrotóxicos, como mostra o gráfico 3.

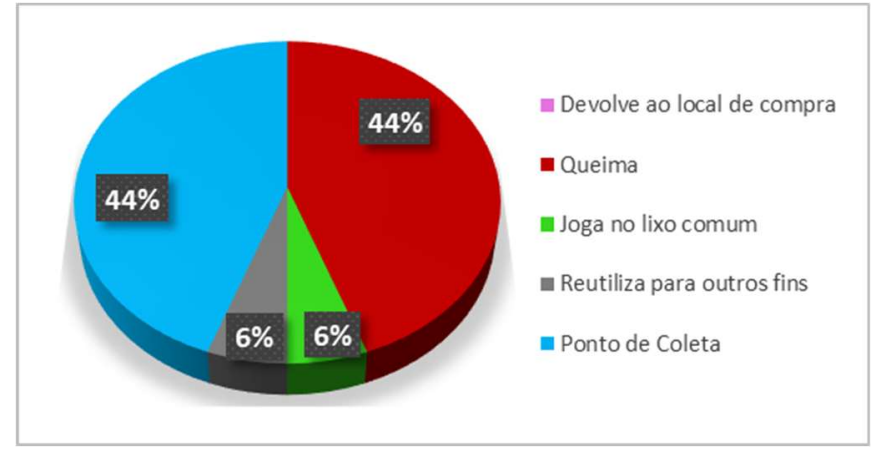

Gráfico 3: Destino final das embalagens vazias dos agrotóxicos, dado pelos agricultores entrevistados.

No que diz respeito ao destino final das embalagens vazias, o manual de uso correto e seguro de produtos fitossanitários/ agrotóxicos da Andef (2008) diz que a legislação brasileira obriga o agricultor a devolvê-las na unidade de recebimento indicada pelo revendedor. Antes da devolução, o agricultor deve separar as embalagens lavadas das contaminadas. $O$ agricultor que não devolver as embalagens ou não separá-las adequadamente poderá ser multado, além de ser enquadrado na Lei de Crimes Ambientais.

Segundo Nunes (2017, citado por SILVA et al., 2017) a destinação final ambientalmente correta das embalagens vazias pode ser realizada através da reciclagem ou incineração, no qual, é determinada pelo tipo de material e nível de contaminação das mesmas. Conforme a NR 31, no item 31.8.15 é vedada em qualquer hipótese, para qualquer fim, a reutilização das embalagens vazias de agrotóxicos, cuja destinação deverá atender à legislação vigente. $\mathrm{O}$ item 31.9.1 da mesma norma exige que os resíduos derivados dos processos produtivos devem ser retirados do local de trabalho, de forma a seguir métodos e procedimentos adequados que não ocasionem contaminação ambiental (BRASIL, 2005).

Os agricultores que afirmaram realizar o descarte correto das embalagens vazias, no qual entregam no ponto de recebimento municipal para embalagens de agrotóxicos, informaram que as juntam por um período de tempo e um único agricultor responsável vai entregar no ponto de coleta que é localizado no município de Milagres/CE. Segundo eles, esse foi o local mais próximo encontrado para recebimento dos mesmos, dificultando ainda mais o procedimento de entrega das embalagens, pois o mesmo localiza-se em outro município de aproximadamente $47 \mathrm{~km}$ de distância. No entanto, os demais relatam da dificuldade de recebimento das embalagens vazias nas cooperativas, explicando o motivo pelos quais fazem o descarte da maneira inadequada.

O estudo de Nogueira et al. (2013) apresentam resultados semelhantes a realidade do comodato, no qual, a pesquisa revelou também que a maior parte $53,1 \%$ dos produtores rurais queima as embalagens após 
o uso, $37,5 \%$ dos pesquisados afirmaram que devolvem as embalagens ao comércio e $9,4 \%$ guardam essas embalagens para devolver ou jogam na serra como destino final.

De acordo com Nogueira et al. (2013) apesar das recomendações sobre o descarte correto das embalagens vazias de agrotóxicos, na prática, ainda evidencia-se o abandono nos locais de pulverização e sua reutilização para outros fins, como por exemplo, para acondicionamento de água e alimentos, bem como a incidência de queima dessas embalagens na agricultura, esses destinos constituem-se em fontes potencialmente poluidoras do ambiente, podendo contaminar mananciais hídricos, meio ambiente e acarretar em problemas de saúde pública que se agravam devido a ingestão de produtos tóxicos.

\section{Lavagem das roupas/EPIs contaminados por agrotóxicos}

Quando perguntados sobre o uso de avental e luvas para lavar as roupas/ EPIs contaminados por agrotóxicos, todos os entrevistados informaram que não utilizam, no entanto, eles destacaram que a lavagem é realizada separada das roupas comuns.

Segundo a NR 31, no item 31.8.13 a limpeza dos equipamentos de proteção deve ser realizada por pessoas treinadas e protegidas (BRASIL, 2005). O que não acontece em pequenas propriedades rurais pelos agricultores, devido à falta de conhecimento dos riscos dessa exposição. Mesmo após a aplicação dos agrotóxicos, a contaminação pelo seu uso pode ocorrer de forma indireta, através da lavagem dos EPIs contaminados. Vale ressaltar que, na maioria das vezes, esses equipamentos são lavados pelas mulheres dos agricultores, o que aumenta os riscos de contaminação entre os membros da família. Além disso, quando esses EPIs são guardados sendo pouco ou nada limpos, é provável que ocorra uma contaminação acumulativa no interior dos EPIs.

Quando questionados sobre a existência na propriedade de um tanque especifico para lavar as roupas/ EPIs contaminados por agrotóxico a resposta foi $89 \%$ não possui e $11 \%$ possui e quando perguntados para onde escoava o efluente da lavagem dessas roupas/ EPIs contaminados, $61 \%$ afirmaram que vai direto para o chão e $39 \%$ para fossa negra. No entanto, sabe-se que esse tipo de lavagem realizada por eles, tem como consequência a contaminação do meio ambiente e lençóis freáticos.

No que se refere a contaminação dos corpos hídricos, ocasionado pela lavagem dos EPIs, os entrevistados contemplados pela pesquisa afirmaram que o efluente da lavagem é direcionado para a fossa negra, sistema usualmente utilizado em zonas rurais. De acordo com Costa (2014), esses sistemas de disposição são amplamente discutidos pelos seus aspectos negativos, pois tem ocasionados problemas ao meio ambiente, saúde e normalmente poluem e contaminam os rios.

De acordo com Carneiro (2015), os impactos ambientais decorrentes da irrigação e dos insumos químicos são diversos e dependendo das características dos solos de cada região, podem propiciar a lixiviação dos produtos químicos para camadas mais profundas, favorecendo a contaminação subterrânea que atinge o lençol freático e as águas superficiais de rios e açudes. A NR 31, item 31.8.13.1 deixa explícito que a limpeza dos equipamentos deverá ser executada de forma a não contaminar poços, rios, córregos e quaisquer outras coleções de água (BRASIL, 2005). No entanto, verifica-se que na realidade isso pouco acontece. 


\section{Sintomas após a aplicação dos agrotóxicos}

Quando perguntados se já tinham sentido algum sintoma após a aplicação dos agrotóxicos, 28\% afirmaram que sim e os outros $72 \%$ afirmaram que não. Dentre os sintomas mencionados os mais comuns e frequentes foram: dor de cabeça, náuseas, tontura, ardência na vista e um caso de derrame após aplicação de agrotóxicos, que podem ou não estar relacionado ao uso do mesmo.

De acordo com Silva et al. (2004, citado por SILVA et al., 2017) o uso de agrotóxicos está associado a sérias doenças e desordens na saúde, incluindo câncer, dano ao sistema nervoso, sistema reprodutivo e outros órgãos, anormalidades no desenvolvimento e comportamento, disfunção hormonal e disfunção do sistema imunológico.

Segundo Carneiro (2015) a frequência ao uso de agrotóxico pode ocasionar intoxicações crônicas e agudas, cujos sintomas variam de acordo com o grupo químico que está inserido, no entanto, os sintomas são: náuseas, dor de cabeça, tontura, vômitos, contrações musculares involuntárias, irritações das conjuntivas, sangramento nasal, fraqueza, desmaios, efeitos neurotóxicos retardados, lesões hepáticas, arritmias cardíacas, alergias, asma brônquica, irritações nas mucosas, doença de Parkinson e cânceres.

Sendo assim, os sintomas mencionados pelos agricultores da pesquisa em estudo podem estar relacionados aos sintomas de intoxicação mencionados acima, no entanto, segundo Londres (2011), a desinformação dos trabalhadores sobre os riscos da exposição aos agrotóxicos, além do medo de reconhecer os sintomas de intoxicação, dificulta os registros de intoxicação por agrotóxicos na CAT, pois poucos procuram assistência médica quando apresentam alguns desses sintomas e resistem em admitir a relação com o uso desse produto agrícola, além de não acreditar que a manipulação dos mesmos podem ter consequências graves a saúde deles.

No entanto, a maioria dos entrevistados no estudo ressaltou não sentir nenhum sintoma após manuseio desses insumos, porém, segundo Neves et al. (2013) esse manuseio inadequado pode resultar em intoxicações aguda, e as vezes, esses efeitos ocorrem após um determinado período de tempo, no qual percebe-se isso, pelos registros de intoxicações do Sistema Nacional de Informações Toxicológicas (Sinitox), onde há uma grande ocorrência de efeitos adversos, principalmente os de longo prazo, podendo determinar doenças crônicas. Ou seja, os 72\% dos agricultores da amostra, que alegaram não sentir nada até o momento, não estão isentos dos riscos de contaminação, devido ao alto grau de periculosidade desses produtos, além de que os efeitos podem surgir com o passar dos anos, através do surgimento de doenças crônicas.

\section{CONCLUSÕES}

Através do presente estudo foi possível conhecer o perfil socioeconômico dos agricultores familiares, identificar os procedimentos e os riscos da utilização de agrotóxicos e as possibilidades de contaminações ambientais e humanas devido ao emprego do mesmo, além de verificar a utilização de equipamentos de proteção individual no manuseio de agrotóxicos em pequenas propriedades rurais no município de Juazeiro do Norte/CE. 
Verificou-se a predominância de trabalhadores do gênero masculino no campo, com baixos níveis de escolaridade e de modo geral a ausência de aplicação de medidas de controle de segurança no processo de produção agrícola, com apenas $11 \%$ da amostra possuindo e fazendo utilização do kit completo de EPIs. No entanto, notou-se a predominância do uso de agrotóxicos pelos agricultores, com manipulação de produtos extremamente tóxico e medianamente tóxico, com um alto grau de periculosidade ambiental, que devido a exposição do trabalhador ao risco necessitaria do desenvolvimento de métodos efetivos de controle deles e de melhoria das condições de trabalho.

Contudo, observa-se que na pesquisa em estudo os agricultores são trabalhadores rurais autônomos, não respondem legalmente a nenhuma organização, fazendo com que eles que ditem seu próprio regime de trabalho. Sendo assim, a ineficiência na aplicação de medidas de controle de segurança como o cumprimento da NR 31 e principalmente a utilização de EPIs, deve-se ausência de informação sobre os riscos, baixa escolaridade, perpetuação de antigas práticas de cultivo, quesito financeiro, sentimento de imunidade ao perigo e a falta de assistência de políticas públicas voltadas para o trabalhador rural, no qual, ficam expostos a riscos que são prejudicais para saúde dos mesmos.

Sendo assim, os problemas decorrentes do uso de agrotóxicos na agricultura, deixou de ser um problema restrito ao campo e tornou-se um problema de saúde pública e ambiental, devido aos riscos de contaminação ao meio ambiente e ao aumento de casos de intoxicações e demais doenças relacionadas ao uso desses produtos, no qual, requer aplicação de medidas de controle de segurança, visando diminuir esses riscos, necessitando de uma maior atuação do setor público no desenvolvimento de políticas públicas direcionadas a capacitação dos produtores rurais no que se refere a correta manipulação dos agrotóxicos.

Diante do exposto, acredita-se na importância da realização de mais estudos exploratórios sobre essa temática da segurança do trabalho no manuseio de agrotóxicos pelos trabalhadores rurais, com o intuito de sensibilizar os órgãos envolvidos, para que possam ofertar um serviço eficaz baseado na política social, ambiental e de saúde no campo agrícola, voltada a implantação de ações que capacitem, forneçam equipamentos de proteção e fiscalizem, afim de dá uma maior assistência aos agricultores familiares de pequenas propriedades rurais, para minimizar os riscos de exposição provenientes do manuseio de agrotóxicos na agricultura.

\section{REFERÊNCIAS}

ABREU, P. H. B.; ALONZO H. G. A.. O agricultor familiar e o uso (in)seguro de agrotóxicos no município de Lavras/MG. Revista Brasileira de Saúde Ocupacional, São Paulo, v.41, p.1-12, 2016. DOI: http://dx.doi.org/10.1590/23176369000130015

AMARAL, S. I. T.. Agroquímicos: Uma alternativa para o ensino de Ciências e sustentabilidade. 2 ed. Curitiba, 2013.

ANDEF. Associação Nacional de Defesa Vegetal. Manual de uso correto e seguro de produtos

fitossanitários/agrotóxicos. 2 ed. São Paulo: ANDEF, 2008.
ANVISA. Agência Nacional de Vigilância Sanitária.

Reclassificação dos agrotóxicos. Brasília: ANVISA, 2019.

BERNARDI, A. C. A.; HERMES, R.; BOFF, V. A.. Manejo e destino das embalagens de agrotóxicos. Revista Perspectiva, Florianópolis, v.42, n.159, p.15-28, 2018.

BRASIL. Decreto n. 4.074, de 4 de janeiro de 2002. Regulamenta a Lei n. 7.802, de 11 de julho de 1989, que dispõe sobre a pesquisa, a experimentação, a produção, a embalagem e rotulagem, o transporte, o armazenamento, a comercialização, a propaganda comercial, a utilização, a importação, a exportação, o destino final dos resíduos e embalagens, o registro, a classificação, o controle, a 
inspeção e a fiscalização de agrotóxicos, seus componentes e afins, e dá outras providências. Brasília: DOU, 2002.

BRASIL. Lei Federal n. 11. 326, de 24 de julho de 2006. Estabelece as diretrizes para a formulação da Política Nacional da Agricultura Familiar e Empreendimentos Familiares Rurais. Brasília: DOU, 2006.

BRASIL. Ministério da Agricultura, Pecuária e Abastecimento. Reclassificação toxicológica dos agrotóxicos. Brasília: MAPA, 2019.

BRASIL. Ministério do Trabalho e Emprego. Portaria MTE $\mathbf{n}$. 3.214, de 08 de junho de 1978. Norma Regulamentadora 6 Equipamento de Proteção Individual. Brasília: MTE, 1978.

BRASIL. Ministério do Trabalho e Emprego. Portaria MTE $\mathbf{n}$. 3.214, de 08 de junho de 1978. Norma Regulamentadora 9 Programa de Prevenção de Riscos Ambientais. Brasília: MTE, 1978.

BRASIL. Ministério do Trabalho e Emprego. Portaria MTE $\mathbf{n}$. 86, de 03 de março de 2005. Norma Regulamentadora 31 Segurança e saúde no trabalho na agricultura, pecuária silvicultura, exploração florestal e aquicultura. Brasília: MTE, 2005.

CARNEIRO, F. F.. Dossiê ABRASCO: um alerta sobre os impactos dos agrotóxicos na saúde. Rio de Janeiro: EPSJV; São Paulo: Expressão Popular, 2015.

CIZENANDO, T. A. L.. Uso de agrotóxicos nas pequenas propriedades produtoras de Banana no município de Ipanguaçu/RN. Monografia (Bacharelado em Ciências e Tecnologia) - Universidade Federal Rural do Semiárido, Angicos, 2012.

COSTA, P. S. A.. Desenvolvimento de uma opção de saneamento rural para pequenos agricultores de Minas Gerais (Itabira). Monografia (Bacharelado em Engenharia Agrícola e Ambiental) - Universidade Federal Fluminense, Niterói, 2014.

PAULA, L. A. C.. Êxodo Rural Seletivo: Reflexões sobre a migração de jovens e mulheres nos espaços rurais. In: ENCONTRO NACIONAL DE GEOGRAFIA AGRÁRIA, 24. Anais. Grande Dourados: UFGD, 2018.

FOLGADO, C. A. R.. Agrotóxicos: um problema invisibilizado. Caderno de estudo, Movimento dos Pequenos Agricultores. Distrito Federal, 2014.

FRANCISCO, M. V.; ALANIZ, E. P.. Interfaces entre a educação do campo e a disciplina de educação física escolar. Revista Reflexão e Ação, Santa Cruz do Sul, v.22, n.2, p.39-67, 2014.

IBGE. Instituto Brasileiro de Geografia e Estatística. Censo Agropecuário. Rio de Janeiro: IBGE, 2017.

IPECE. Instituto de Pesquisa e Estratégia Econômica do Ceará. Perfil Básico Municipal, Juazeiro do Norte. Fortaleza: IPECE, 2016.
ISMAEL, L. L.; GARCIA, H. R. M.; MARTINS, W. A.; AUGUSTO, J.. Saúde, meio ambiente e segurança do trabalho associado ao uso de agrotóxicos. Revista Verde de Agroecologia e Desenvolvimento Sustentável, Pombal, v.10, n.5, p.28-33, 2015. DOI: http://dx.doi.org/10.18378/rvads.v10i5.3731

LONDRES, F.. Agrotóxicos no Brasil: um guia para ação em defesa da vida. Rio de Janeiro: Assessoria e Serviços a Projetos em Agricultura Alternativa, 2011.

LOPES, C. V. A.; ALBUQUeRQUE, G. S. C.. Agrotóxicos e seus impactos na saúde humana e ambiental: uma revisão sistemática. Revista Saúde debate, Rio de janeiro, v.42, n.117, p.518-534, 2018. DOI: http://dx.doi.org/10.1590/0103-1104201811714

NEVES, P. D. M.; BELLINI, M.. Intoxicações por agrotóxicos na mesorregião norte central paranaense, Brasil - 2002 a 2011. Revista Ciênc. Saúde Coletiva, Rio de Janeiro, v.18, n.11, p.3147-3156, 2013. DOI: http://dx.doi.org/10.1590/S1413$\underline{81232013001100005}$

NOGUEIRA, V. B. M.; DANTAS, R. T.. Gestão ambiental de embalagens vazias de agrotóxicos. Revista Tema, Campina Grande, v.14, n.20/21, p.22-34, 2013.

PERES, F.; MOREIRA, J. C.. É veneno ou é remédio?: agrotóxicos, saúde e ambiente. 20 ed. Rio de Janeiro: FIOCRUZ, 2003.

RECENA, M. C. P.; CALDAS, E. D.. Percepção de risco, atitudes e práticas no uso de agrotóxicos entre agricultores de Culturama, MG. Revista de Saúde Pública, São Paulo, v.42, n.2, p.294-301, 2008.

SILVA, J. M. O.; OLIVEIRA, R. P.. Agrotóxicos: uso, contaminações e destino das embalagens nas propriedades de agricultura familiar no município de Paragominas - PA. Monografia (Bacharelado em Engenharia Agronômica) Universidade Federal Rural da Amazônia, Paragominas, 2017.

SILVA, R. F.; FERNANDES, F. C. F.; SOARES, A. C.; CHARMELO, L. C. L.. Uso e manuseio de agrotóxicos pelos agricultores da microbacia do córrego cabeceira do JacutingaCaratinga/MG. Blucher Engineering Proceedings, São Paulo, v.3, n.2, p.164-173, 2016.

SILVEIRA, M. A. S.. Importância do uso de equipamento de proteção individual por agricultores no município de São Sepé/RS. Monografia (Especialização em educação Ambiental) - Universidade Federal de Santa Maria, Santa Maria, 2011.

SINAN. Sistema de Informações de Agravos de Notificação. Dados de intoxicações por agrotóxicos. SINAN, 2017.

VEIGA, M. M.. Agrotóxicos: eficiência econômica e injustiça socioambiental. Revista Ciência e Saúde Coletiva, Rio de Janeiro, v.12, n.1, p.145-152, 2007. DOI: https://doi.org/10.1590/S1413-81232007000100017

A CBPC - Companhia Brasileira de Produção Científica (CNPJ: 11.221.422/0001-03) detém os direitos materiais desta publicação. Os direitos referem-se à publicação do trabalho em qualquer parte do mundo, incluindo os direitos às renovações, expansões e disseminações da contribuição, bem como outros direitos subsidiários. Todos os trabalhos publicados eletronicamente poderão posteriormente ser publicados em coletâneas impressas sob coordenação da Sustenere Publishing, da Companhia Brasileira de Produção Científica e seus parceiros autorizados. Os (as) autores (as) preservam os direitos autorais, mas não têm permissão para a publicação da contribuição em outro meio, impresso ou digital, em português ou em tradução. 